\title{
Conforto térmico de um cômodo construído com diferentes tipos de revestimentos
}

\section{Daniel Machado Alves Pereira*, Bernat Vinolas Prat e Flaviana Tavares Vieira Teixeira}

Instituto de Ciência e Tecnologia. Universidade Federal dos Vales do Jequitinhonha e Mucuri. Campus JK. Rodovia MGT 367, km 583, no 5000. Bairro Alto do Jacuba. Diamantina-MG, Brasil (CEP 39100-000). *E-mail: danielmap10@gmail.com.

Resumo. 0 conforto térmico mantém uma íntima relação com a qualidade de vida e a produtividade de todos os seres vivos, pois está relacionado com o seu grau de satisfação e acomodação com a temperatura ambiente. Assim, o presente artigo objetiva demonstrar como os materiais utilizados em uma construção interferem na variação da temperatura, consequentemente no conforto térmico e na ecoeficiência de um ambiente. Para isto criou-se uma planilha de dados, que mostra a variação da temperatura ao longo de um dia em um cômodo construído de $16 \mathrm{~m}^{2}$. Com estes dados é possível obter informações sobre como o tipo de bloco, reboco e materiais isolantes interferem no conforto térmico de um edifício. A análise dos dados não mostrou grandes variações de temperatura para blocos comumente utilizados, contudo, concluiu-se que dependendo do material utilizado na construção pode-se interferir na sua ecoeficiência.

Palavras-chave: Ambiente construído; Conforto térmico; Transferência de calor; Variação de temperatura.

\begin{abstract}
Thermal comfort of a room built with different types of coverings. Thermal comfort maintains an intimate relation with the quality of life and productivity of all living beings, considering that it is related to their degree of satisfaction and accommodation with the ambient temperature. Thus, the present article aims to demonstrate how the materials used in a construction interfere in the temperature variation, consequently in the thermal comfort and ecoefficiency of an environment. For this, a data sheet was created, which shows the variation of temperature over a day in a $16 \mathrm{~m}^{2}$ built room. With this data it is possible to obtain information on how the types of block, plaster and insulation materials interfere in the thermal comfort of a building. The data analysis did not show large temperature variations for commonly used blocks, however, it was concluded that depending on the material used in the construction can interfere in its ecoefficiency.
\end{abstract}

Keywords: Built environment; Thermal comfort; Heat transfer; Temperature variation.
Recebido:

27/11/2018

Aceito:

11/04/2019

Publicado:

30/04/2019

Acesso aberto

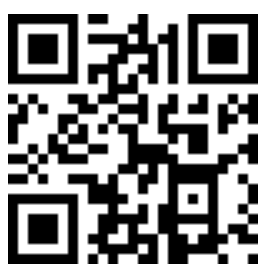

ORCID

(D) 0000-0001-9084-3586 Daniel Machado Alves Pereira

(D) 0000-0002-0002-2811 Bernat Vinolas Prat

(D) 0000-0003-3797-1778

Flaviana Tavares

Vieira Teixeira 


\section{Introdução}

0 conforto térmico que de forma bem sucinta e objetiva representa o grau satisfação e acomodação de um ser à temperatura de um determinado ambiente é um conceito extremamente importante para a análise da qualidade de vida, produtividade e bem-estar das pessoas, animais e plantas. Por se relacionar com a temperatura, como o próprio nome sugere, ele está sujeito às estações do ano, local e até mesmo questões fisiológicas, porém através de fatos empíricos sabe-se muito bem que existe uma determinada faixa de temperatura em que se há um maior nível de satisfação do corpo.

No século XXI um importante quesito de estudo são os fatores que interferem na qualidade de vida e a produtividade. Como bem afirma Silva (2001)

As empresas de hoje estão a todo instante almejando a qualidade total, pois sabem que a competitividade, saúde, segurança e produtividade são as exigências do mercado mundial (Silva, 2001, p. 9).

Segundo Silva (1998), a iluminação inadequada, sistema de ar condicionado super ou subdimensionados e outros fatores desajustados, podem interferir no sucesso das tarefas realizadas.

De acordo com Olgyay (1973) e Pimenta et al. (2015), a zona de conforto representa aquele ponto no qual a pessoa necessita de consumir a menor quantidade de energia para se adaptar ao ambiente circundante.

Observando esta definição de conforto, um quesito importante que aparece na vida cotidiana é o conforto térmico, que seria o nível de sensação de bem-estar com relação à temperatura. Deste modo, o conforto térmico pode ser entendido como um conceito subjetivo, que depende de diversos fatores e vária de pessoa para pessoa (Pimenta et al., 2015).

Contudo, considerando que o homem mantém a temperatura interna do corpo aproximadamente a $36,5^{\circ} \mathrm{C}$, há uma temperatura ideal na qual ele estará em um estado de conforto térmico.

0 conforto térmico além da preocupação com o bem-estar, também se relaciona intimamente com 0 desempenho na realização de tarefas, uma vez que executar tarefas em um ambiente com melhores condições de bem-estar, melhora significativamente $o$ rendimento e diminui o desgaste por fatores externos à tarefa (Dias, 2013).

Observando isto, esta pesquisa apresenta um estudo da relação de alguns blocos utilizados para construção civil com a sua influência no conforto térmico de um ambiente.

\section{Referencial teórico}

Quando pensando nos padrões do século XXI, este conceito pode ser obtido de forma a utilizar recursos naturais com um menor gasto de energia, como utilizando ventilação natural ou revestimentos e blocos adequados.

Plantas também são muito afetadas pelas condições de luminosidade, temperatura e conforto térmico. Bezerra Neto et al. (2005) afirma que a alface é uma planta que se adapta a determinadas condições de luminosidade e temperatura, e isto surte efeitos no seu desenvolvimento.

Ramos (1995) mostrou que um sombreamento de $30 \%$ em uma plantação de alface acarretou em uma maior produção, altura e massa da planta.

As características do ambientes podem ser amenizadas ou contornadas com a ajuda de avanços tecnológicos e com o estudo de como se fazer a adequação em um ambiente.

0 conforto térmico também é levado em consideração na construção de galpões e locais para a confinação de 
animais, como em granjas, onde os animais têm um maior rendimento e uma maior produção quando estão termicamente confortáveis no ambiente.

0 abrigo animal tem por objetivo dar-lhe conforto, para que possa aumentar a sua produção. Esse conforto não será medido da mesma forma com que essa sensação se faz ao ser humano, mas sob a forma de produção ou produtividade.

As instalações recebem diretamente a ação do clima (insolação, temperatura, vento, chuva, umidade do ar), devendo por isso ser construída com a finalidade principal de diminuir estas influências que podem agir negativamente nos animais (o excesso de calor, por exemplo). Ao nível do edifício, os fatores que interferem na modificação destas condições são as paredes, altura do pé direito, piso e principalmente $\mathrm{o}$ material de cobertura, que recebe toda a radiação solar incidente e é o maior responsável pelo microclima gerado dentro do edifício (Sevegnani et al., 1994, p. 1).

0 calor, que fisicamente representa a energia térmica em movimento, é transferido de um lugar para outro apenas quando há uma diferença no gradiente de temperatura (Jorge, 2011).

A transferência de calor pode ser realizada por condução, convecção e radiação. Quando há uma diferença de gradiente de temperatura entre superfícies sólidas, o tipo de transmissão de calor que ocorre através do meio é chamado de condução; quando há transferência de calor em um fluido em movimento o nome dado é convecção; já a radiação é caracterizada por não necessitar de um meio para que ocorra a transferência de calor.

Todas as superfícies, a uma temperatura não nula, emitem energia na forma de ondas eletromagnéticas. Assim na ausência de um meio que as intercale, existe uma transferência de calor por radiação entre duas superfícies que se encontram à diferentes temperaturas (Mesquita, 2011).

Um edifício é capaz de armazenar energia térmica a partir de uma propriedade chamada inércia térmica. Esta propriedade é muito importante quando se quer analisar o comportamento deste edifício quanto ao conforto térmico (Costa, 2014).

Em dias frios, parte do calor que o edifício recebe durante o dia é acumulado em forma de energia na sua estrutura devido à inércia térmica. Durante a noite, quando a temperatura tende a diminuir, esta energia é liberada em forma de calor, por causa da diferença de gradiente de temperatura, e acaba por aquecer os ambientes (Santos e Pimentel, 2012).

A inércia térmica é proporcional à quantidade de estruturas presentes em um edifício, ou seja, quanto mais estruturas ele possuir (mais "pesado" ele for), maior será a sua capacidade de acumular energia proveniente do meio exterior (Jorge, 2011).

Juntando todos os fatores inerentes à inércia térmica, com um planejamento arquitetônico correto, com a utilização de materiais adequados e também com características adequadas, é possível conseguir um bom nível de conforto térmico para um ambiente.

Para se determinar o nível de transferência de calor de um bloco são vários os métodos empregados, métodos estes, que já foram amplamente testados e comprovados, como o método da placa quente aquecida descrito na ABNT NBR 15220:2005, que consiste basicamente no fornecimento de energia para gerar um gradiente de temperatura em corpos de prova, utilizando termopares para medir as temperaturas obtidas (ABNT, 2005).

Através de cálculos matemáticos é possível determinar a transferência de calor do material. Observando isto, é possível calcular a transmissão térmica e, 
consequentemente, também calcular para um edifício. Logo com estes valores, é possível estimar o conforto térmico de um determinado ambiente.

\section{Metodologia}

Para a obtenção dos dados foi desenvolvido, uma planilha de dados no qual se entra com dados pré-estabelecidos e através deles são feitos cálculos para gerar um gráfico mostrando a variação da temperatura externa e interna do cômodo ao longo de um dia. Foram realizados cincos casos na planilha proposta (Tabela 1 ).

Tabela 1. Detalhe dos casos realizados na planilha.

\begin{tabular}{|c|l|c|}
\hline Casos & \multicolumn{1}{|c|}{ Especificação dos casos } & \multicolumn{1}{|c|}{$\begin{array}{c}\text { Peso do bloco } \\
\text { (kg) }\end{array}$} \\
\hline 1 & Bloco cerâmico $(9 \times 19 \times 19) \mathrm{cm}+2 \mathrm{~cm}$ de reboco & 2,3 \\
\hline 2 & $\begin{array}{l}\text { Bloco cerâmico }(9 \times 19 \times 19) \mathrm{cm}+2 \mathrm{~cm} \text { de reboco }+ \text { isolante EPS } \\
\text { (Poliestireno expandido moldado) }\end{array}$ & 2,3 \\
\hline 3 & Bloco de concreto $(50 \times 20 \times 15) \mathrm{cm}+2 \mathrm{~cm} \mathrm{de} \mathrm{reboco}$ & 15 \\
\hline 4 & $\begin{array}{l}\text { Bloco de concreto }(50 \times 20 \times 15) \mathrm{cm}+2 \mathrm{~cm} \text { de reboco }+ \text { isolante } \\
\text { EPS }\end{array}$ & 15 \\
\hline 5 & $\begin{array}{l}\text { Bloco cerâmico }(9 \times 19 \times 19) \mathrm{cm}+2 \mathrm{~cm} \text { de reboco }+5 \mathrm{~cm} \mathrm{de} \\
\text { isolante de lã de vidro }\end{array}$ \\
\hline
\end{tabular}

${ }^{1}$ Dados sobre os blocos cerâmicos foram obtidos em Cerâmica Saturno (2018) e sobre os blocos de concreto em Mendes \& Rodrigues (2018).

\section{Dados gerais}

Com fins de estudos do comportamento dos diferentes tipos de materiais foi escolhido um cômodo fictício, totalmente fechado, com $4 \mathrm{~m} \times 4 \mathrm{~m}\left(16 \mathrm{~m}^{2}\right)$ e com $2,5 \mathrm{~m}$ de pé direito, totalizando um volume total de $40 \mathrm{~m}^{3}$.

Foi considerado a laje como ideal, ou seja, não havendo troca de calor com o ambiente interno. Deste modo a área total de paredes do cômodo é $40 \mathrm{~m}^{2}$.

\section{4 paredes $\times(2,5 \mathrm{~m} \times 4,0 \mathrm{~m})=40 \mathrm{~m}^{2}$}

A variação da temperatura do ambiente ao longo do dia foi obtida no Instituto Nacional de Meteorologia (INMET) para o dia 08/08/2017, com temperatura típica da Cidade de Diamantina, Minas Gerais, como descrito na Tabela 2. 
Tabela 2. Variação da temperatura do ambiente ao longo do dia.

\begin{tabular}{|c|c|}
\hline Tempo (h) & Temperatura ( $^{\circ} \mathbf{C}$ ) \\
\hline $0: 00-1: 00$ & 12,1 \\
\hline $1: 00-2: 00$ & 12,0 \\
\hline $2: 00-3: 00$ & 12,1 \\
\hline $3: 00-4: 00$ & 11,6 \\
\hline $4: 00-5: 00$ & 11,4 \\
\hline $5: 00-6: 00$ & 10,0 \\
\hline $6: 00-7: 00$ & 9,90 \\
\hline $7: 00-8: 00$ & 9,10 \\
\hline $8: 00-9: 00$ & 8,90 \\
\hline $9: 00-10: 00$ & 9,10 \\
\hline $10: 00-11: 00$ & 11,5 \\
\hline $11: 00-12: 00$ & 13,2 \\
\hline $12: 00-13: 00$ & 14,9 \\
\hline $13: 00-14: 00$ & 16,9 \\
\hline $14: 00-15: 00$ & 18,9 \\
\hline $15: 00-16: 00$ & 21,3 \\
\hline $16: 00-17: 00$ & 22,9 \\
\hline $17: 00-18: 00$ & 22,8 \\
\hline $18: 00-19: 00$ & 23,0 \\
\hline $19: 00-20: 00$ & 22,4 \\
\hline $20: 00-21: 00$ & 19,7 \\
\hline $21: 00-22: 00$ & 17,2 \\
\hline $22: 00-23: 00$ & 16,6 \\
\hline $23: 00-0: 00$ & 15,1 \\
\hline
\end{tabular}

Levou-se em conta que cada parede externa do cômodo continha $2 \mathrm{~cm}$ de argamassa ou reboco tradicional $\left(2.000 \mathrm{~kg} / \mathrm{m}^{3}\right)$ e que para colocar um bloco em cima do outro utilizou-se $1 \mathrm{~cm}$ do mesmo reboco.

\section{A planilha de dados}

Conceito 1. Programa criado é baseado em três conceitos: duas formulações e um cálculo de aplicação de métodos numéricos.

$$
q=\frac{\Delta T}{R}
$$

Equação 1

Na Equação 1, q representa o fluxo de calor que passa pelo cômodo. Sendo $\Delta \mathrm{T}$ a variação da temperatura e $\mathrm{R}$ a resistência equivalente de todos os elementos que compõe a parede (tipo de bloco e reboco).

\section{Conceito 2}

$Q=m \cdot c \cdot \Delta T$

Equação 2

Rearranjando os termos da Equação 2, temos:

$$
\Delta \mathrm{T}=\frac{\mathrm{Q}}{\mathrm{m} \cdot \mathrm{c}}
$$

Equação 3

A Equação 3 representa a quantidade de energia e mostra que o incremento ou diminuição da temperatura é inversamente proporcional ao calor específico e à quantidade de massa.

Conceito 3. A temperatura inicial da casa é considerada, arbitrariamente, $20{ }^{\circ} \mathrm{C}$, já a temperatura exterior é obtida a partir dos dados meteorológicos coletados.

Baseando-se em intervalor de 1 min (60 s), a planilha de dados calcula o fluxo de calor a partir da Equação 1. Como a unidade de $q$ é J/s, multiplicando o seu valor por $60 \mathrm{~s}$, obtém-se a energia a cada incremento de tempo.

Este valor representa a energia que servirá para promover a mudança de temperatura no interior do cômodo. A partir da Equação 3 encontra-se qual a variação de temperatura no interior da casa e da parede.

Considerando que um dia contém $1.440 \mathrm{~min}$ ( $60 \mathrm{~s} \times 24 \mathrm{~h}$ ), a planilha de dados refaz estes cálculos para cada um destes incrementos de tempo, totalizando $24 \mathrm{~h}$ ou um dia completo.

A partir destes dados é plotado um gráfico que informa a evolução da temperatura interior e exterior ao longo do tempo. Também é obtido a maior e menor temperatura registrada dentro do cômodo.

\section{Cálculos das entradas}

Para um tijolo cerâmico com dimensões $9 \mathrm{~cm} \times 19 \mathrm{~cm} \times 19 \mathrm{~cm}$ com peso de 2,3 kg (Cerâmica Saturno) a 
difusividade da parede é fornecida pela Equação 4:

Difusividade $=\frac{1}{\mathrm{R}} \quad$ Equação 4

Como a resistência interna e externa é de $0,04\left(\mathrm{~m}^{2}{ }^{\circ} \mathrm{C} / \mathrm{W}\right)$ :

\section{Difusividade $=25\left(\mathrm{~W} / \mathrm{m}^{2}{ }^{\circ} \mathrm{C}\right)$}

A difusividade térmica também é calculada pela Equação 5:

$R_{\text {equivalente }}=\frac{R_{\text {tijolo }} \times A_{\text {tijolo }}+R_{\text {reboco }} \times A_{\text {reboco }}}{A_{\text {total }}}$
Difisividade $=\frac{\lambda}{\mathrm{e}}$

Equação 5

e $\lambda$ pela Equação 6:

$\lambda=\frac{1}{\text { Difusividade }}$

Equação 6

Onde e é a espessura do bloco. Logo, a argamassa apresenta $\lambda=$ $1,80\left(\mathrm{~W} / \mathrm{m}^{2 \circ} \mathrm{C}\right)$ e resistência térmica 0,05 $\left(\mathrm{m}^{2}{ }^{\circ} \mathrm{C} / \mathrm{W}\right)$.

A resistência equivalente da parede é obtida de acordo com a Equação 7:

Então,

$$
R_{\text {equivalente }}=\frac{[0,23 \times(0,19 \times 1 \mathrm{~m})]+[0,05 \times(0,01 \times 1 \mathrm{~m})]}{[0,19 \times 1 \mathrm{~m}]+[0,01 \times 1 \mathrm{~m}]}=0,221\left(\mathrm{~m}^{2}{ }^{\circ} \mathrm{C} / \mathrm{W}\right)
$$

Sendo que o $\lambda$ do tijolo cerâmico $0,23 \mathrm{~m}^{2}{ }^{\circ} \mathrm{C} / \mathrm{W}$. Com o $\lambda$ do reboco igual a $1,80 \mathrm{~W} / \mathrm{m}^{2 \circ} \mathrm{C}$ e a espessura do reboco externo igual a $0,02 \mathrm{~cm}$, obtém-se da Equação 4:

$$
\begin{gathered}
\text { Difisividade }=\frac{1,08}{0,02}=90\left(\mathrm{~W} / \mathrm{m}^{2}{ }^{\circ} \mathrm{C}\right) \\
\lambda=\frac{1}{90}=0,0111\left(\mathrm{~m}^{2}{ }^{\circ} \mathrm{C} / \mathrm{W}\right)
\end{gathered}
$$

A resistência equivalente é dada pela soma das resistências, assim, a resistência total é a resistência do reboco interno somada com a resistência do bloco mais a resistência do reboco externo, como segue na Equação 8:

$R$ equivalente $=R_{1}+R_{2}+R_{3}$ Equação 8

Em que $\mathrm{R}_{1}$, $\mathrm{R}_{2} \quad \mathrm{e} \quad \mathrm{R}_{3}$ são respectivamente a resistência do reboco interno, resistência da parede e a resistência do reboco externo.

Assim,

$$
R_{\text {equiralente }}=0,0111+0,221+0,0111=0,2432\left(\mathrm{~m}^{2}{ }^{\circ} \mathrm{C} / \mathrm{W}\right)
$$


Como difusividade é o inverso da resistência térmica, a difusividade total da parede será:

$$
\text { Difusividade }=\frac{1}{R}=\frac{1}{0,2432}=4,11\left(\mathrm{~W} / \mathrm{m}^{2}{ }^{\circ} \mathrm{C}\right)
$$

Para a entrada da densidade efetuou-se o cálculo da densidade média da parede para $1 \mathrm{~m}^{2}$ de área.

0 número de tijolos contidos em $1 \mathrm{~m}^{2}$ depende do comprimento do bloco e da espessura de argamassa utilizada, de acordo com a Equação 9:

$1 \mathrm{~m}^{2}$

(altura do bloco x espessura do bloco)x (comprimen to do blocox espessura do bloco) Equação 9

Que para o bloco cerâmico $(9 \times 19$ $x$ 19) $\mathrm{cm}$ com $0,01 \mathrm{~m}$ de reboco entre cada bloco foi de 25 tijolos $/ \mathrm{m}^{2}$.
A massa total da parede em questão é a soma da massa do bloco com a massa de reboco utilizada nas duas extremidades do bloco.

\section{$\left(25\right.$ tijolos $\left.\left./ \mathrm{m}^{2} \times 2,30 \mathrm{~kg}\right)+2 \times\left[(0,09 \mathrm{~m} \times 1 \mathrm{~m} \times 0,01 \mathrm{~m}) \times 2000 \mathrm{~kg} / \mathrm{m}^{3}\right)\right]=61,1 \mathrm{~kg}$}

A massa total da camada de $2 \mathrm{~cm}$ de reboco utilizados do lado interno e externo da parede é de: 2 x $(0,02 \mathrm{~m} \mathrm{x}$ $1 \mathrm{~m}^{2} \times 2000 \mathrm{~kg} / \mathrm{m}^{3}$ ) $=80 \mathrm{~kg}$.

Somando-se as duas, encontrouse a massa total e dividindo pela espessura total da parede em $1 \mathrm{~m}^{2}:(2 \mathrm{~cm}$ de reboco interno $+9 \mathrm{~cm}$ do bloco $+2 \mathrm{~cm}$ de reboco externo) $=13 \mathrm{~cm}$ de espessura. Encontrou-se a densidade total da parede:

$$
\frac{61,1 \mathrm{Kg}+80 \mathrm{Kg}}{1 \mathrm{~m}^{2} \times 0,13 \mathrm{~m}}=1085,384 \mathrm{~kg} / \mathrm{m}^{3}
$$

Após efetuar estes cálculos, todas as entradas da planilha de dados foram encontradas (espessura da parede, difusividade interior e exterior da parede, massa total e densidade média), além dos outros dados já estabelecidos como o calor específico, volume do cômodo e área da parede.

Analogamente, foram efetuados os mesmo cálculos para cada um dos casos propostos.

\section{Resultados e discussão}

A plotagem dos gráficos mostrados nas Figuras 1, 2, 3, 4 e 5 forneceram os resultados mostrados na Tabela 3.

Tabela 3. Variação da temperatura interna do cômodo ao logo de um dia em cada tipo de bloco.

\begin{tabular}{|l|c|}
\hline Tipo de bloco & $\mathbf{\Delta T}\left({ }^{\circ} \mathbf{C}\right)$ \\
\hline Bloco cerâmico $(9 \times 19 \times 19) \mathrm{cm}$ & 2,8 \\
\hline Bloco cerâmico $(9 \times 19 \times 19) \mathrm{cm}+$ isolante EPS & 0,8 \\
\hline Bloco de concreto $(50 \times 20 \times 15) \mathrm{cm}$ & 2,0 \\
\hline Bloco de concreto $(50 \times 20 \times 15) \mathrm{cm}+$ isolante EPS & 0,5 \\
\hline Bloco cerâmico $(9 \times 19 \times 19) \mathrm{cm}+5 \mathrm{~cm}$ de isolante de lã de vidro & 0,9 \\
\hline
\end{tabular}


A análise do gráfico que representa apenas do bloco cerâmico (Figura 1) mostrou que além de obter a maior amplitude térmica registrada, também houve variação da temperatura em vários horários do dia, a menor temperatura registrada foi $16,79{ }^{\circ} \mathrm{C}$, aproximadamente em $780 \mathrm{~min}(13: 00 \mathrm{~h})$.

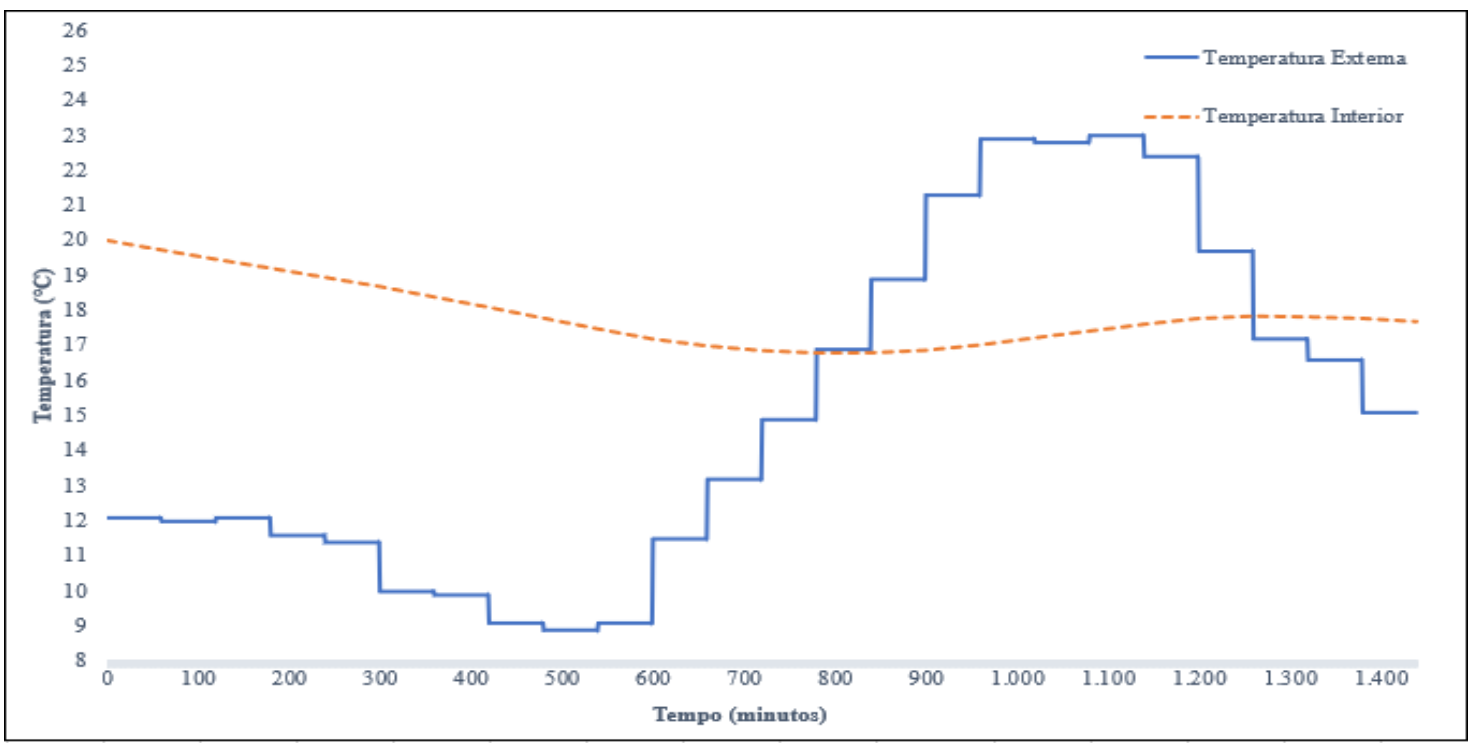

Figura 1. Variação da temperatura interna e externa ao longo de um dia para o bloco cerâmico $(9 \times 19 \times 19) \mathrm{cm}$.

No gráfico do bloco cerâmico com isolante EPS (Figura 2) observa-se que a temperatura interna manteve-se estável durante o todo o dia, apresentando $19,09^{\circ} \mathrm{C}$ como a menor temperatura no começo da tarde (aproximadamente em $900 \mathrm{~min}$, que representa 15:00 h).

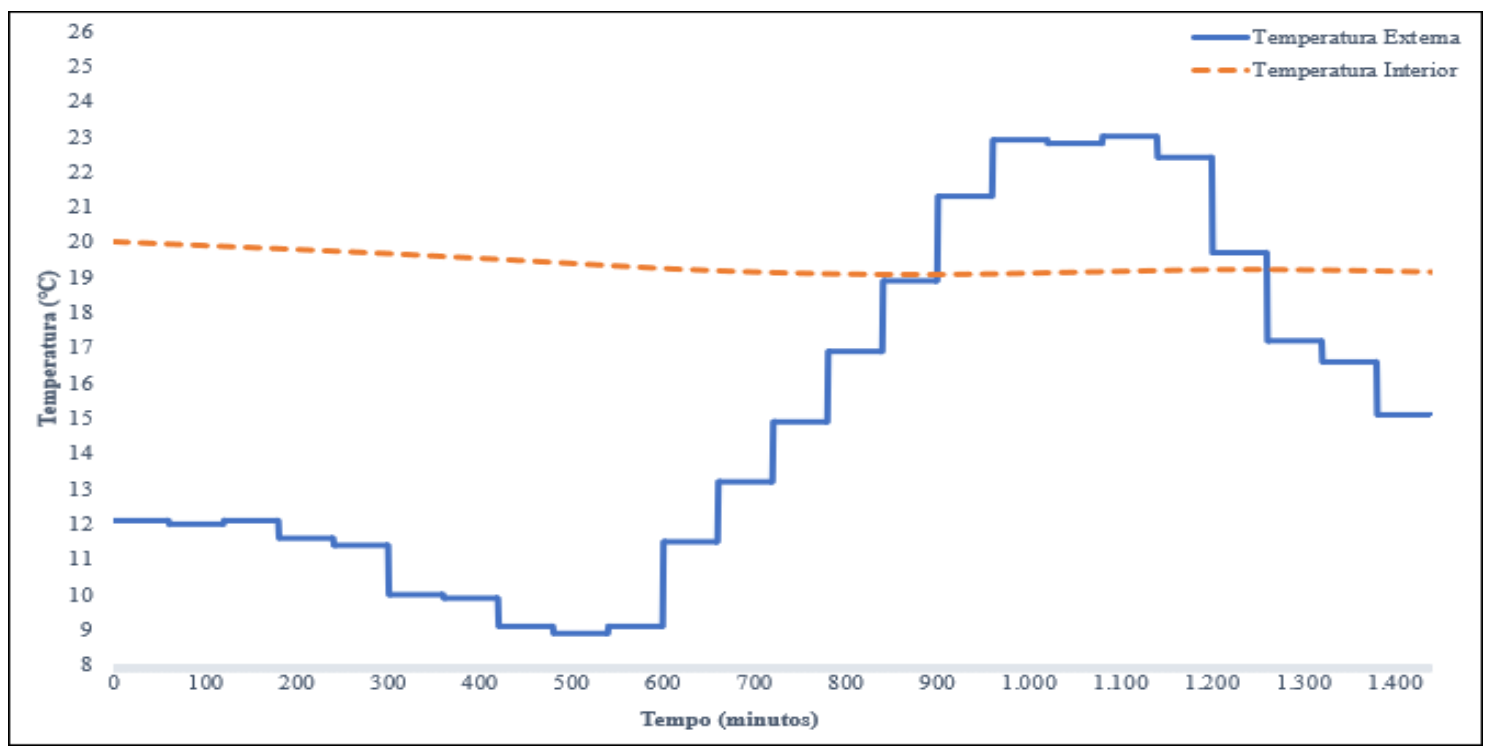

Figura 2. Variação da temperatura interna e externa ao longo de um dia para o bloco cerâmico $(9 \times 19 \times 19) \mathrm{cm}+$ isolante EPS. 
Para o gráfico apenas do bloco de concreto (Figura 3), vê-se claramente que a temperatura interna voltou a ter uma maior variação, apresentando $17,74{ }^{\circ} \mathrm{C}$ como a menor temperatura, aproximadamente em $840 \mathrm{~min}(14: 00 \mathrm{~h})$.

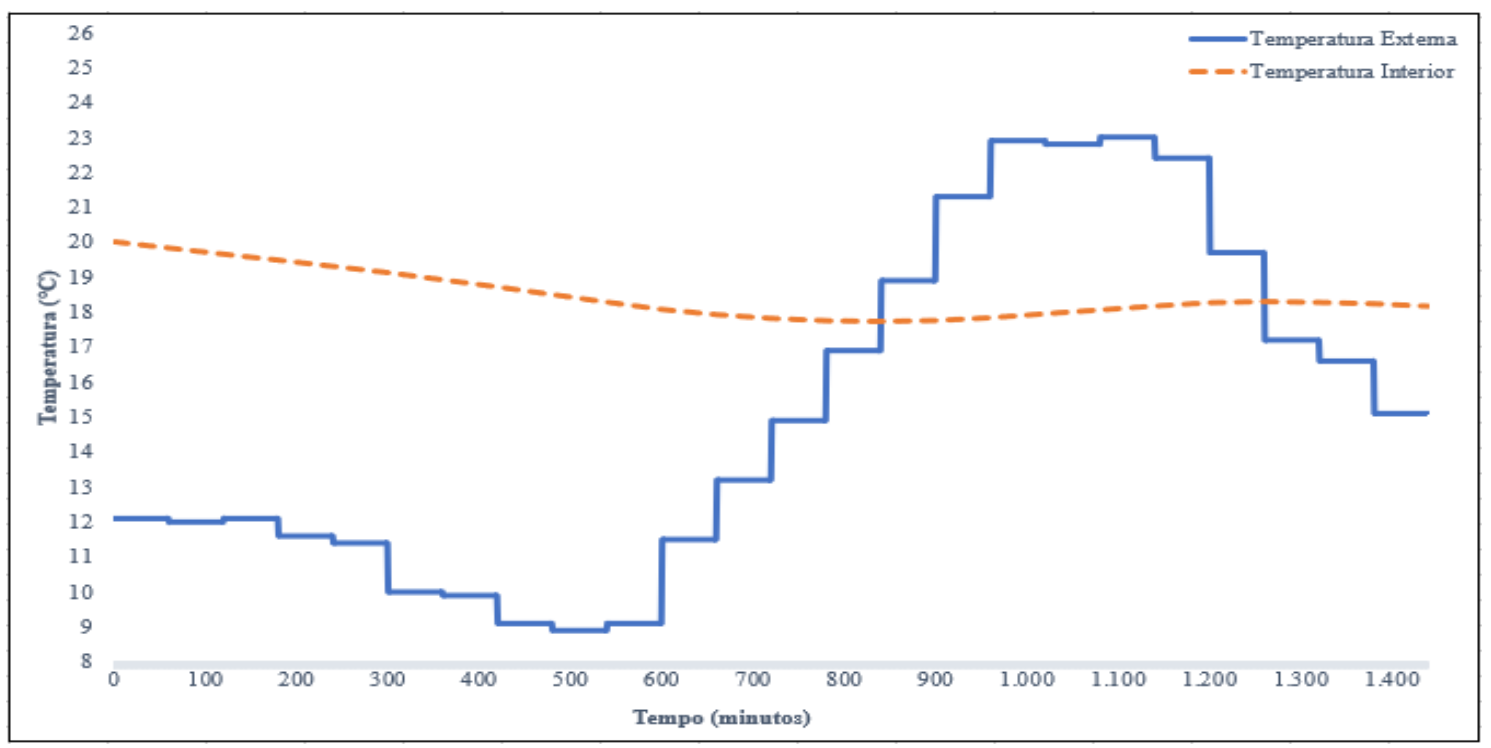

Figura 3. Gráfico da variação da temperatura interna e externa ao longo de um dia para o bloco de bloco de concreto $(50 \times 20 \times 15) \mathrm{cm}$.

A Figura 4 correspondente ao bloco de concreto com isolante EPS, que teve a menor variação de temperatura durante todo o dia e também que foi o caso no qual a temperatura se manteve mais constante. A menor temperatura registrada foi $19,43^{\circ} \mathrm{C}$, aproximadamente em $904 \min$ (15: $04 \mathrm{~h}$ )

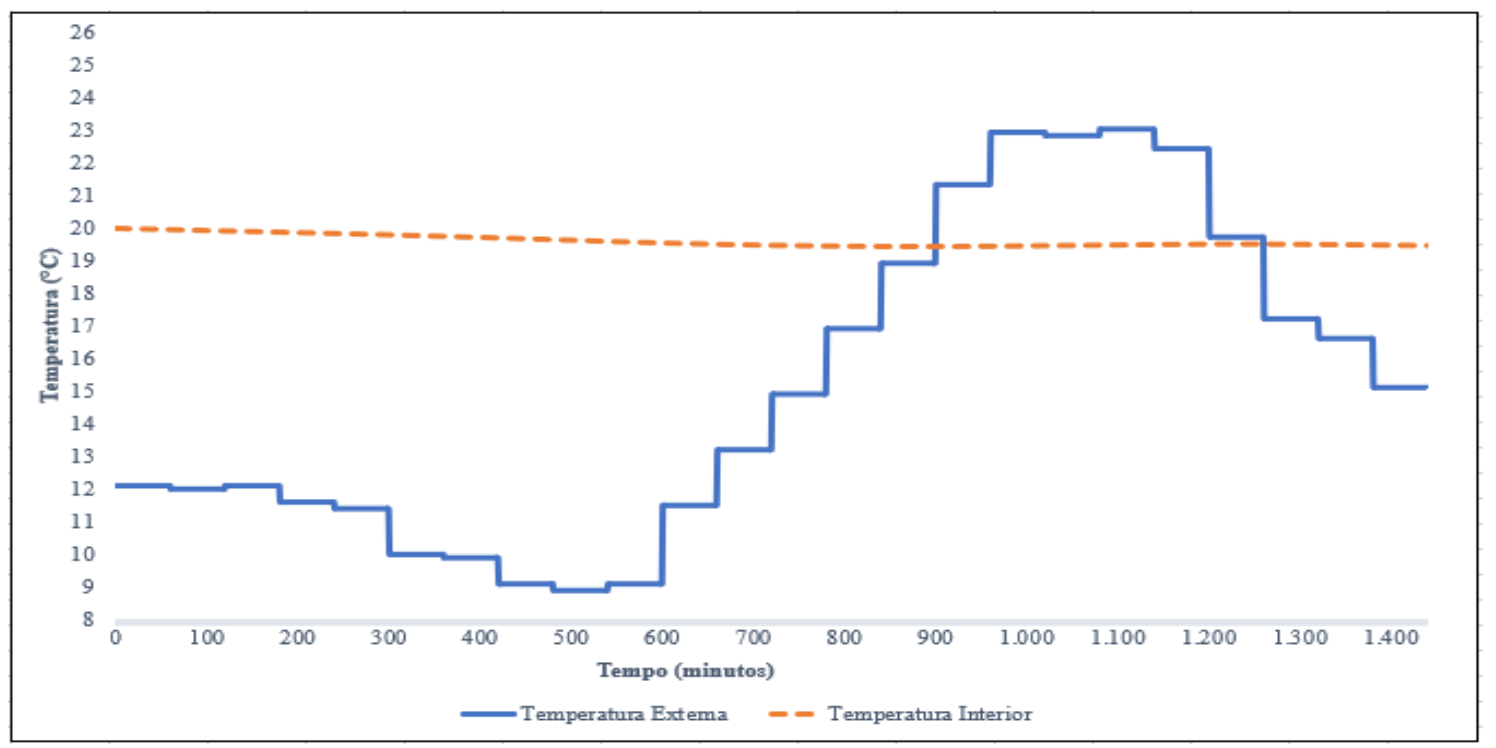

Figura 4. Gráfico da variação da temperatura interna e externa ao longo de um dia para o bloco de concreto (50 x $20 \times 15) \mathrm{cm}+$ isolante EPS. 
Já o gráfico que representa o bloco cerâmico com isolante de lã de vidro (Figura 5) ficou em uma posição intermediária em relação aos outros casos com amplitude de $0,9^{\circ} \mathrm{C}$, apresentando $19,01{ }^{\circ} \mathrm{C}$ na menor temperatura, aproximadamente em 900 $\min (15: 00 \mathrm{~h})$.

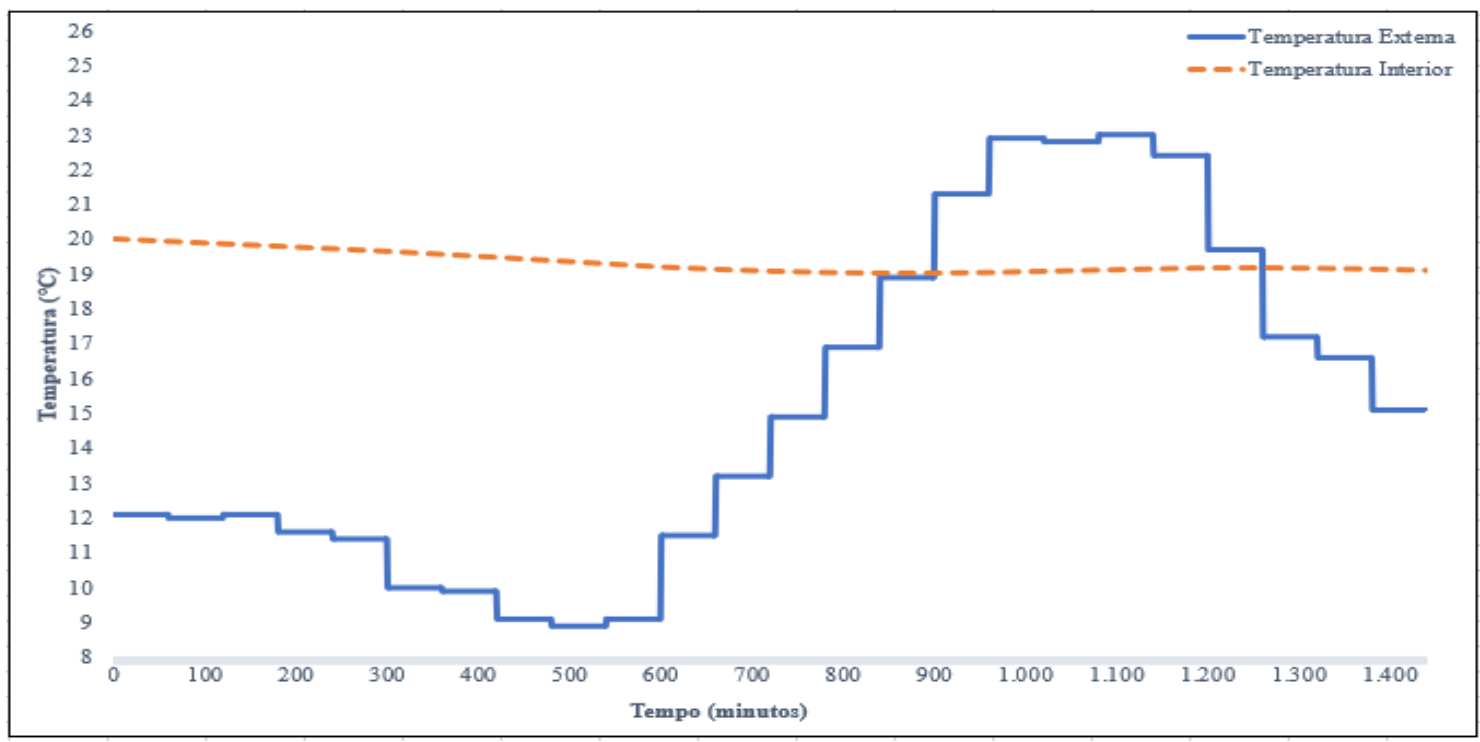

Figura 5. Gráfico da variação da temperatura interna e externa ao longo de um dia para o bloco cerâmico $(9 \times 19 \times 19) \mathrm{cm}+5 \mathrm{~cm}$ de isolante de lã de vidro.

De acordo com a definição de conforto térmico, o melhor resultado obtido foi para o bloco e concreto com isolante EPS (Figura 4), que apresentou a menor amplitude na temperatura interna, $0,5^{\circ} \mathrm{C}$. Aliado a isto, o seu gráfico também mostrou que foi o caso no qual a temperatura do cômodo manteve-se mais estável durante todo o dia. 0 pior resultado foi o bloco cerâmico sem isolante (Figura 1), com uma variação da temperatura interna de $2,8^{\circ} \mathrm{C}$. Além deste fato, também foi o caso que apresentou maior mudança de temperatura em vários horários do dia.

Outro aspecto interessante apresentado nos resultados foi o horário em que se obteve a menor temperatura registrada em cada um dos casos. Reiterando que todos eles foram realizados para uma mesma temperatura externa, no mesmo dia, estes horários mostraram-se relativamente bem distintos, havendo a discrepante diferença de 3 hdo melhor resultado para o pior.

No caso 1 a menor temperatura registrada aproximadamente às 13: $00 \mathrm{~h}$, no caso 2 , às $15: 00 \mathrm{~h}$, no caso 3 , às $14: 00 \mathrm{~h}$, no 4 às $15: 04 \mathrm{~h}$ e no 5 às 15:00 h.

Em um primeiro momento para uma análise de um cômodo com finalidade familiar, com cozinha, sala de estar, copa, entre outros, este resultado pode não fazer muita diferença. Entretanto, novamente, é importante frisar que para algumas situações específicas, como experimentos em laboratórios para produção de vacinas e remédios, isto pode fazer diferença. Este fato reforça mais uma vez a importância do controle do conforto térmico e das variações de temperatura. 


\section{Considerações finais}

Com os experimentos realizados observou-se que:

1) 0 uso de isolantes térmicos podem levar a uma diminuição entre $2,1^{\circ} \mathrm{C}$ e $2,5^{\circ} \mathrm{C}$ da variação da temperatura interna ao longo de um dia.

2) Não há diferenças significativas entre o uso de isolante EPS e o uso de isolante de lã de vidro, devido à baixa diferença nos resultados obtidos.

3) 0 uso de blocos de concreto e cerâmicos não influem de forma discrepante na variação da temperatura e consequentemente do conforto térmico de uma casa para uma família. Por outro lado, dependendo da aplicação a escolha destes blocos podem trazer significativas diferenças, por exemplo em um ambiente controlado para viveiro plantas, animais ou também em pesquisas laboratoriais em que a variação de graus ou alguns centésimos de graus façam diferença.

Deste modo, os fatores mais relevantes na construção de uma casa ou um ambiente devem ser o custo e a rigidez pretendida quanto a variação de temperatura, já que com as informações colhidas por este trabalho mostrou-se que não há diferenças significativas quanto ao uso de tijolos cerâmicos e de concreto e também quanto ao uso de isolante EPS e de lã de vidro.

Contudo, reforça-se que em ambiente que necessitam de um maior controle da variação da temperatura interna e de conforto térmico, deve-se aliar fatores como cobertura, ventilação, tipo de bloco utilizado, custo, clima vivenciado e isolantes térmicos, pois a junção de todos estes fatores propiciam um alto grau de conforto térmico para um ambiente e maior ecoeficiência.

\section{Material suplementar}

No material suplementar, encontra-se a planilha de dados a partir da qual foi realizada esta pesquisa, disponível em https://doi.org/ $10.21438 /$ rbgas.061206s, com acesso livre.

\section{Conflitos de interesse}

Os autores declaram não haver conflitos de interesse.

\section{Referências}

ABCP - Associação Brasileira de Cimento Portland. 2017. Disponível em: $<$ http://www.abcp.org.br/cms/basico-sobrecimento/aplicacoes/solo-cimento/>. Acesso em: 11 fev. 2018.

ABNT - Associação Brasileira de Normas Técnicas. ABNT NBR 15220:2005 Desempenho térmico de edificações Parte 4 - Medição da resistência térmica e da condutividade térmica pelo princípio da placa quente protegida. Rio de Janeiro: ABNT, 2005.

Bezerra Neto, F.; Rocha, R. C. C.; Negreiros, M. Z.; Rocha, R. H.; Queiroga, R.C.F. Produtividade de alface em função de condições de sombreamento e temperatura e luminoidade elevadas. Horticultura Brasileira, v. 23, n. 2, p. 189-192, 2005. http://doi.org/10.1590/S0102-05362005 000200005

Cerâmica Saturno. Produtos. 2018. Disponível em: <http://www.ceramica saturno.com.br/Produtos.pdf>. Acesso em: 01 ago. 2018.

Costa, S. P. L. Armazenamento de energia térmica através de materiais de mudança de fase. Porto: Universidade do Porto, 2014. (Dissertação de mestrado).

Dias, A. A.C. Avaliação da perceção da influência do conforto térmico na produtividade. Minho: Universidade do Minho, Escola de engenharia, 2013. (Dissertação de mestrado).

Ferreira Filho, E. D. M. Construção com solo cimento. Cepla.gov, 2014. Disponível em: 
<http://www.ceplac.gov.br/radar/Artigos/a rtigo7.htm>. Acesso em: 11 fev. 2018.

INMET - Instituto Nacional de Meteorologia. Disponível em: <http://www.inmet.gov.br/ portal/>. Acesso em: 22 jun. 2018.

Jorge, L. Determinação do coeficiente de transmissão. Covilhã: Universidade da Beira Interior, 2011. (Dissertação de mestrado).

Mendes \& Rodrigues Lda. Artefactos de Cimentos. Categorias de produtos. 2018. Disponível em: <http://www.mendesrodri gues.pt/product/category/1>. Acesso em: 01 ago. 2018.

Mesquita, M. D. S. Matéria e radiação: uma abordagem contextualizada ao ensino de Física. Brasília: UNB, 2011.

Olgyay, V. Design with climate: Bioclimatic approach to architectural regionalism. New Jersey: Princeton University Press, 1973.

Pimenta, A. I.; Oliveira, B.; Campos, J.; João Neto, M.; Pereira, R.. Conceito de Conforto Térmico Humano. Porto: Faculdade de Engenharia da Universidade do Porto, 2015. Disponível em: <https://paginas.fe.up.pt/ $\sim$ projfeup/submit_14_15/uploads/relat_Q1F QI04_1.pdf>. Acesso em: 01 ago. 2018.
Ramos, J. E. L. Sombreamento e tipos de recipientes na formação de mudas e produção em alface. Mossoró: ESAM, 1995. (Dissertação de mestrado).

Santos, F. O.; Pimentel, M. R. S. Edificações e conforto térmico: a moradia como fonte de aprendizagem. Caminhos de Geografia, v. 13, n. 44, p. 265-285, 2012. Disponível em: <http://www.seer.ufu.br/index.php/caminh osdegeografia/article/viewFile/20876/1130 >. Acesso em: 01 ago. 2018.

Sevegnani, K. B.; Ghelfi Filho, H.; Silva, I. J. O. Comparação de vários materiais de cobertura. Scientia Agricola, v. 51, n. 1, p. 17 , 1994. https://doi.org/10.1590/S010390161994000100001

Silva, L. B. D. Análise da relação entre produtividade e conforto térmico: o caso dos digitadores do Centro de Processamento de Dados e Cobrança da Caixa Econômica Federal do Estado de Pernambuco. Florianópolis: UFSC, 2001. (Tese de doutorado).

Silva, W. R. Tecnologia, microeletrônica e trabalho. Revista da Unipê, v. 1, n. 3, p. 59-68, 1998. 
Rev. Bras. Gest. Amb. Sustent., 2019, vol. 6, n. 12, p. 81-92. 